\title{
THE TOXICITY OF VARIOUS NON-ELECTROLYTES TO HUMAN SPERMATOZOA AND THEIR PROTECTIVE EFFECTS DURING FREEZING
}

\author{
D. W. RICHARDSON* AND R. M. F. S. SADLEIR $\dagger$ \\ Endocrine Unit, University College Hospital, London, \\ and Wellcome Institute of Comparative Physiology, \\ Zoological Society of London, London
}

(Received 29th October 1966)

\begin{abstract}
Summary. At concentrations varying from $2.5 \%$ to $10.0 \%$, glycerol, dimethyl sulphoxide, ethylene glycol, methyl formamide and methyl acetamide had approximately equally toxic effects on human spermatozoa; whereas dimethyl formamide and dimethyl acetamide were considerably more toxic at the same concentrations.

Glycerol and ethylene glycol afforded an equal protective action to human spermatozoa during freezing and thawing, approximately $50 \%$ of the original motility being retained, but negligible protection was exhibited by methyl formamide, dimethyl formamide, methyl acetamide and dimethyl acetamide. Only $34 \%$ of the original motility was retained when human spermatozoa were frozen in the diluent containing dimethyl sulphoxide.
\end{abstract}

\section{INTRODUCTION}

The fertility of human semen after preservation by freezing has so far proved to be low when compared with that of frozen semen from some other species of mammals (Sadleir, 1966). The only detailed report on the fertility of human frozen semen seems to be by Sawada (1964) who obtained eleven pregnancies from 230 inseminations of 150 women. The low level of fertility of frozen semen may be due to the fact that inseminations are almost invariably carried out on women whose marriages have been infertile, although a contributory factor will be the somewhat reduced motility of the spermatozoa as a result of the freezing process.

The agent most commonly used for the protection of spermatozoa has been glycerol (Sherman, 1963; Freund \& Wiederman, 1966) although some work has been done utilizing dimethyl sulphoxide (Zimmerman, Maude \& Moldawer, 1964). The effects of other agents, previously described as protecting animal cells during freezing, were investigated and compared with glycerol and dimethyl sulphoxide. They were selected from a group of agents reported by

Present addresses:

* Department of Obstetrics and Gynecology, Medical Center, University of Michigan, Ann Arbor, U.S.A.

† Department of Biological Sciences, Simon Fraser University, Burnaby 2, B.C., Canada. 
Nash (1962) as protecting erythrocytes during the cooling process. Farrant (1964) had also investigated the protective action of these substances on smooth muscle and has reported on their low toxicity when injected into mice.

\section{MATERIAL AND METHODS}

\section{Estimation of motility and progression}

A thin slide preparation of spermatozoa was made and examined at room temperature (about $20^{\circ} \mathrm{C}$ ). The motility of each preparation was estimated by one of us (D.R.) using: (a) a visual low power estimate to $5 \%$ on each of five fields, and (b) a count of all motile and immotile spermatozoa in either a half or a quarter of each of five different fields. The mean of these ten estimates was used as the index of motility of the sample. In addition, the degree of progression of the motile spermatozoa was rated on a scale from 0 (immotile) to 10 (moving so rapidly that tail movement could not be observed).

\section{Protective agents investigated}

The following substances were investigated: glycerol, dimethyl sulphoxide, dimethyl acetamide, methyl acetamide, dimethyl formamide, methyl formamide and ethylene glycol.

\section{Toxicity testing}

Semen ejaculates obtained from medical students were allowed to liquefy at room temperature and their original motilities determined. Specimens having original motilities below $55 \%$ were discarded. Semen from a group of five donors was tested against four concentrations of each protective agent, but the donors in the group were not the same five individuals for each of the seven agents.

The semen from each individual donor was divided into four aliquots which were then each slowly diluted $1: 1$ with $0.9 \%$ saline containing twice the required final concentration of the various protective agents $(5,10,15$ and $20 \%$ ) and left at room temperature until rated. Motilities and progression ratings of the spermatozoa were estimated at 30 and $60 \mathrm{~min}$ after the initial dilution.

\section{Evaluation of protective action}

To test the protective effect of the various agents during freezing, concentrations were selected on the basis of the toxicity tests. Fresh liquefied semen specimens from each of another group of six donors were split into aliquots which were then diluted 1:5 with solutions of the semen protective agents in $0.9 \%$ saline. In a second experiment, further specimens from the same donors were diluted in the same manner with solutions of the protective agents constituted in Norman-Johnson-1 solution (Freund \& Wiederman, 1966). Egg yolk was included in all cases to a final concentration of $15 \%$.

After slow dilution, the semen was equilibrated for $30 \mathrm{~min}$ at room temperature, pipetted in $0.5-\mathrm{ml}$ quantities into glass ampoules which were then sealed and cooled at $5^{\circ} \mathrm{C} / \min$ to $4^{\circ} \mathrm{C}$ and then $1^{\circ} \mathrm{C} / \mathrm{min}$ to $-40^{\circ} \mathrm{C}$. The ampoules were then stored in liquid nitrogen. They were thawed 39 to 42 days later in a 
water-bath at $30^{\circ} \mathrm{C}$ and removed when the last ice crystal melted. The motility of the sample was estimated 15 min later at room temperature.

\section{Toxicity tests}

\section{RESULTS}

The average initial motility of the semen samples was $61.3 \% \quad(\mathrm{sE}=$ $0.80 \%$ ). The effect of the various treatments is expressed as the percentage loss in motility. Table 1 gives the mean loss in motility after 30 and 60 min for each agent at four different concentrations and the significance of the difference between these means. Examination of Table 1 shows that the different substances had markedly different effects on the motility of spermatozoa although

TABLE 1

MEAN PERGENTAGE LOSS OF MOTILITY IN DIFFERENT GONGENTRATIONS OF PROTEGTIVE AGENTS

\begin{tabular}{|c|c|c|c|c|c|c|c|}
\hline \multirow{2}{*}{ Agent } & \multicolumn{7}{|c|}{ Concentration } \\
\hline & $2.5 \%$ & $P<$ & $5.0 \%$ & $P<$ & $7.5 \%$ & $P<$ & $10.0 \%$ \\
\hline $\begin{array}{l}30 \text { mimutes after dilution } \\
\text { Glycerol } \\
\text { Dimethyl sulphoxide } \\
\text { Dimethyl acetamide } \\
\text { Dimethyl formamide } \\
\text { Methyl acetamide } \\
\text { Methyl formamide } \\
\text { Ethylene glycol }\end{array}$ & $\begin{array}{r}9 \cdot 2 \pm 2 \cdot 5 \\
8 \cdot 4 \pm 1 \cdot 2 \\
9 \cdot 6 \pm 5 \cdot 1 \\
11 \cdot 0 \pm 4 \cdot 5 \\
9 \cdot 0 \pm 2 \cdot 8 \\
7 \cdot 4 \pm 3 \cdot 4 \\
8 \cdot 0 \pm 2 \cdot 2\end{array}$ & $\begin{array}{c}0 . \overline{001} \\
\overline{-} \\
0 . \overline{1} \\
- \\
\overline{-} \\
0.01\end{array}$ & $\begin{array}{l}16 \cdot 4 \pm 3 \cdot 8 \\
15 \cdot 2 \pm 1 \cdot 0 \\
19 \cdot 6 \pm 3 \cdot 7 \\
23 \cdot 0 \pm 2 \cdot 3 \\
13 \cdot 0 \pm 0 \cdot 7 \\
11 \cdot 6 \pm 2 \cdot 2 \\
14 \cdot 2 \pm 0 \cdot 8\end{array}$ & $\begin{array}{l}0 . \overline{0} \\
0.001 \\
0.01 \\
0.05 \\
0.05 \\
0.01\end{array}$ & $\begin{array}{l}21 \cdot 2 \pm 3 \cdot 6 \\
18 \cdot 2 \pm 0 \cdot 8 \\
36 \cdot 4 \pm 3 \cdot 8 \\
43 \cdot 4 \pm 7 \cdot 6 \\
18 \cdot 0 \pm 2.9 \\
17 \cdot 2 \pm 1 \cdot 6 \\
18 \cdot 8 \pm 1 \cdot 5\end{array}$ & $\begin{array}{l}0.01 \\
0.001 \\
0.001 \\
0.01 \\
0.001 \\
0.001 \\
0.001\end{array}$ & $\begin{array}{l}34 \cdot 6 \pm 3 \cdot 9 \\
33 \cdot 6 \pm 2 \cdot 0 \\
76 \cdot 2 \pm 1 \cdot 6 \\
78 \cdot 0 \pm 7 \cdot 8 \\
33 \cdot 4 \pm 3 \cdot 5 \\
33 \cdot 0 \pm 2 \cdot 4 \\
28 \cdot 8 \pm 1 \cdot 2\end{array}$ \\
\hline $\begin{array}{l}60 \text { minutes after dilution } \\
\text { Glycerol } \\
\text { Dimethyl sulphoxide } \\
\text { Dimethyl acetamide } \\
\text { Dimethyl formamide } \\
\text { Methyl acetamide } \\
\text { Methyl formamide } \\
\text { Ethylene glycol }\end{array}$ & $\begin{array}{l}18 \cdot 0 \pm 2 \cdot 9 \\
15 \cdot 8 \pm 2 \cdot 6 \\
10 \cdot 2 \pm 2 \cdot 9 \\
17 \cdot 4 \pm 4 \cdot 7 \\
14 \cdot 0 \pm 1 \cdot 4 \\
20 \cdot 0 \pm 3 \cdot 4 \\
14 \cdot 8 \pm 2 \cdot 0\end{array}$ & $\begin{array}{l}-\overline{0} \\
0 \cdot 05 \\
0.001 \\
0.01 \\
0.05 \\
-\overline{05}\end{array}$ & $\begin{array}{l}25 \cdot 0 \pm 3 \cdot 7 \\
21.6 \pm 1 \cdot 0 \\
24 \cdot 6 \pm 1 \cdot 8 \\
31 \cdot 4 \pm 4 \cdot 0 \\
19 \cdot 0 \pm 1 \cdot 8 \\
24 \cdot 2 \pm 3 \cdot 3 \\
18 \cdot 8 \pm 0.6\end{array}$ & $\begin{array}{l}-\overline{001} \\
0 \cdot 001 \\
0 \cdot 01 \\
0 \cdot 001 \\
- \\
0 . \overline{05}\end{array}$ & $\begin{array}{l}27 \cdot 6 \pm 2 \cdot 5 \\
27 \cdot 0 \pm 1 \cdot 4 \\
48 \cdot 2 \pm 3 \cdot 9 \\
61 \cdot 6 \pm 9 \cdot 3 \\
29 \cdot 8 \pm 2 \cdot 4 \\
30 \cdot 8 \pm 2 \cdot 4 \\
23 \cdot 8 \pm 2 \cdot 2\end{array}$ & $\begin{array}{l}0.01 \\
0.001 \\
0.001 \\
0.01 \\
0.001 \\
0.001 \\
0.01\end{array}$ & $\begin{array}{l}42 \cdot 6 \pm 5 \cdot 0 \\
48 \cdot 0 \pm 3 \cdot 5 \\
86 \cdot 2 \pm 1 \cdot 9 \\
88 \cdot 4 \pm 5 \cdot 2 \\
43 \cdot 4 \pm 3 \cdot 3 \\
48 \cdot 8 \pm 4 \cdot 1 \\
34 \cdot 4 \pm 2 \cdot 8\end{array}$ \\
\hline
\end{tabular}

Mean of five determinations \pm standard error. The intermediate columns show the degree of significance between the means in adjacent columns.

the second 30 min only reflected differences already shown in the first 30-min period. With the exception of dimethyl formamide and dimethyl acetamide, there appeared to be no consistent pattern in the degree of decrease in motility with increasing concentration of protective agent. However, in the case of these two substances, there was a fairly regular doubling in the loss of motility for each $2.5 \%$ increase in their concentrations. The mean progression ratings showed that dimethyl sulphoxide, methyl acetamide and methyl formamide had effects similar to glycerol upon the spermatozoa in concentrations up to $7.5 \%$ for $30 \mathrm{~min}$, and $5 \%$ for $60 \mathrm{~min}$; but dimethyl formamide and dimethyl acetamide markedly inhibited spermatozoal movement in concentrations above $5 \%$ (Table 2 ).

In high concentrations most of the protective agents had marked inhibitory effects, with one exception, namely ethylene glycol, in which spermatozoa 
showed little reduction in progression (except over $10 \%$ concentrations) and this characteristic persisted over $60 \mathrm{~min}$. Because of the subjective nature of the progression rating technique, statistical tests were not applied.

\section{Assessment of protective action}

The concentrations used in the evaluation of the agents' protective ability during freezing were based upon the results of the toxicity testing; it was decided to use about a $20 \%$ loss in motility over 30 min during dilution as the

TABLE 2

MEAN PROGRESSION RATINGS AT DIFFERENT GONGENTRATIONS OF PROTECTIVE AGENTS

\begin{tabular}{|c|c|c|c|c|c|c|c|c|c|}
\hline \multirow{2}{*}{ Agent } & \multirow{2}{*}{$\begin{array}{l}\text { Original } \\
\text { rating }\end{array}$} & \multicolumn{4}{|c|}{30 minutes after dilution } & \multicolumn{4}{|c|}{60 minutes after dilution } \\
\hline & & $2.5 \%$ & $5 \%$ & $7 \cdot 5 \%$ & $10 \%$ & $2 \cdot 5 \%$ & $5 \%$ & $7.5 \%$ & $10 \%$ \\
\hline $\begin{array}{l}\text { Glycerol } \\
\text { Dimethyl sulphoxide } \\
\text { Dimethyl acetamide } \\
\text { Dimethyl formamide } \\
\text { Methyl acetamide } \\
\text { Methyl formamide } \\
\text { Ethylene giycol }\end{array}$ & $\begin{array}{l}8 \cdot 4 \\
8 \cdot 0 \\
8 \cdot 2 \\
8 \cdot 2 \\
8 \cdot 8 \\
8 \cdot 0 \\
8 \cdot 8\end{array}$ & $\begin{array}{l}7 \cdot 8 \\
7 \cdot 6 \\
7 \cdot 8 \\
8 \cdot 0 \\
7 \cdot 6 \\
7 \cdot 6 \\
8 \cdot 8\end{array}$ & $\begin{array}{l}7 \cdot 2 \\
7 \cdot 4 \\
6 \cdot 6 \\
7 \cdot 0 \\
7 \cdot 8 \\
6 \cdot 8 \\
8 \cdot 8\end{array}$ & $\begin{array}{l}6 \cdot 2 \\
6 \cdot 8 \\
4 \cdot 4 \\
4 \cdot 8 \\
6 \cdot 2 \\
6 \cdot 2 \\
7 \cdot 4\end{array}$ & $\begin{array}{l}5 \cdot 4 \\
4 \cdot 8 \\
2 \cdot 0 \\
2 \cdot 0 \\
4 \cdot 2 \\
4 \cdot 0 \\
6 \cdot 2\end{array}$ & $\begin{array}{l}7 \cdot 0 \\
6 \cdot 6 \\
7 \cdot 4 \\
7 \cdot 2 \\
6 \cdot 8 \\
6 \cdot 0 \\
7 \cdot 6\end{array}$ & $\begin{array}{l}6 \cdot 4 \\
6 \cdot 4 \\
5 \cdot 6 \\
5 \cdot 8 \\
6 \cdot 6 \\
5 \cdot 4 \\
7 \cdot 2\end{array}$ & $\begin{array}{l}6 \cdot 2 \\
6 \cdot 2 \\
3 \cdot 8 \\
3 \cdot 0 \\
5 \cdot 4 \\
5 \cdot 1 \\
7 \cdot 0\end{array}$ & $\begin{array}{l}4 \cdot 4 \\
3 \cdot 6 \\
1 \cdot 4 \\
1 \cdot 2 \\
3 \cdot 2 \\
2 \cdot 0 \\
5 \cdot 6\end{array}$ \\
\hline
\end{tabular}

TABLE 3

MOTILITY AND PROGRESSION RATING OF SPERMATOZOA AFTER FREEZING AND STORAGE FOR 6 WEEKS (MEAN FOR SIX DONORS)

\begin{tabular}{|c|c|c|c|c|}
\hline \multirow[b]{2}{*}{ Agent } & \multicolumn{2}{|c|}{$0.9 \%$ Saline } & \multicolumn{2}{|c|}{ Norman-Fohnson-1 solution } \\
\hline & $\begin{array}{c}\text { Motility } \\
( \pm 1 S . E .)\end{array}$ & Progression & $\begin{array}{c}\text { Motility } \\
( \pm 1 S . E .)\end{array}$ & Progression \\
\hline $\begin{array}{l}\text { Original } \\
7.5 \% \text { glycerol } \\
7.5 \% \text { dimethyl sulphoxide } \\
5.0 \% \text { dimethyl acetamide } \\
5.0 \% \text { dimethyl formamide } \\
7.5 \% \text { methyl acetamide } \\
7.5 \% \text { methyl formamide } \\
7.5 \% \text { ethylene glycol }\end{array}$ & $\begin{array}{c}61 \cdot 0 \pm 2 \cdot 3 \% \\
30 \cdot 8 \pm 1 \cdot 8 \% \\
23 \cdot 2 \pm 2.2 \% \\
<5 \% \\
<5 \% \\
<5 \% \\
<5 \% \\
29.5 \pm 2.4 \%\end{array}$ & $\begin{array}{l}7 \cdot 8 \\
5 \cdot 2 \\
4 \cdot 7 \\
- \\
- \\
- \\
- \\
5 \cdot 5\end{array}$ & $\begin{array}{c}61 \cdot 0 \pm 3 \cdot 1 \% \\
34 \cdot 2 \pm 3 \cdot 5 \% \\
25 \cdot 8 \pm 2 \cdot 5 \% \\
<5 \% \\
<5 \% \\
<5 \% \\
<5 \% \\
32 \cdot 7 \pm 3 \cdot 5 \%\end{array}$ & $\begin{array}{l}7 \cdot 5 \\
5 \cdot 8 \\
3 \cdot 8 \\
- \\
- \\
- \\
- \\
5 \cdot 2\end{array}$ \\
\hline
\end{tabular}

maximum decrease practicable, to enable the extra loss incurred during freezing to be investigated. On this basis, the following concentrations of the agents were used to evaluate their protective ability during freezing: glycerol, dimethyl sulphoxide, methyl acetamide, methyl formamide and ethylene glycol at concentrations of $7.5 \%$; dimethyl acetamide and dimethyl formamide at concentrations of $5 \%$.

\section{Protective action during freezing}

Dimethyl acetamide, dimethyl formamide, methyl acetamide and methyl formamide had a negligible protective action, the spermatozoa, after freezing 
and thawing in solutions of these substances, had levels of motility below the minimum assessable by the methods used (Table 3 ).

The motilities, after thawing, of spermatozoa frozen in saline solutions of glycerol or ethylene glycol were very similar, but the motility was significantly lower with dimethyl sulphoxide when compared statistically to glycerol $(P<0.01)$ and ethylene glycol $(P<0.05)$. The general motility after thawing was slightly, but not significantly, higher when Norman-Johnson-1 solution was used. In this medium, the post-thaw motility of spermatozoa in dimethyl sulphoxide was significantly lower than in glycerol $(P<0.05)$ but not significantly lower than in ethylene glycol. After freezing, storage and thawing, the progression rating had dropped in all three substances. Again, ethylene glycol had a protective action similar to that of glycerol, but dimethyl sulphoxide was more inhibiting to the progression of spermatozoa.

\section{DISGUSSION}

Dimethyl sulphoxide and glycerol are the only substances of the group tested in this study, whose effect on human spermatozoa has been previously reported (Zimmerman et al., 1964). After freezing, storage and thawing, these workers reported loss of motilities of $62 \%$ for $10.0 \%$ glycerol, $75 \%$ for $10.0 \%$ dimethyl sulphoxide and $81 \%$ for $5.3 \%$ dimethyl sulphoxide. In the present study the losses of motility were 44 to $49 \%$ for $7.5 \%$ glycerol and 58 to $62 \%$ for $7.5 \%$ dimethyl sulphoxide, so that it would appear that this more successful recovery may be due to $7.5 \%$ being nearer to the optimal concentration of these substances required for freezing. Sawada (1964) found that concentrations of glycerol higher than $9 \cdot 1 \%$ depressed the motility of spermatozoa before freezing, and considered that $7.7 \%$ was the optimal concentration of glycerol for preservation. Zimmerman et al. (1964) maintained that the higher the motility of the spermatozoa in the sample before freezing, the better the survival of spermatozoa after freezing. No evidence of such a correlation was found in this study.

Emmens \& Blackshaw (1950) found that $7.5 \%$ ethylene glycol protected rabbit spermatozoa somewhat during freezing. They also investigated the properties of human seminal plasma but did not report on the effect of ethylene glycol on human whole semen. The data reported here indicate that the protective action of ethylene glycol is similar to that of glycerol which suggests that the fertility of human semen frozen in these agents should be compared. Jones (1965) has reported that the best recovery rates of ram semen were obtained after freezing in mixed solutions of $7 \%$ glycerol and $1.5 \%$ dimethyl sulphoxide in combination. It is possible that this approach will result in higher recovery rates.

\section{ACKNOWLEDGMENTS}

We would like to thank Dr J. Farrant for his help and encouragement.

Purified dimethyl sulphoxide (Syntex) was provided by the courtesy of Mr D. M. Moreau. 


\section{REFERENCES}

Emmens, C. W. \& Blackshaw, A. W. (1950) The low temperature storage of ram, bull and rabbit spermatozoa. Aust. vet. 7. 26, 226.

Farrant, J. (1964) Pharmacological actions and toxicity of dimethyl sulphoxide and other compounds. which protect smooth muscle during freezing. 7. Pharm. Pharmac. 16, 472.

Freund, M. \& Wemerman,, J. (1966). Factors affecting the dilution, freezing and storage of human semen. 7. Reprod. Fert. $11,1$.

Jones, R. C. (1965) The use of dimethyl sulphoxide, glycerol and reconstituted skim milk for the preservation of ram spermatozoa. II. The influence of diluent composition and processing time during freezing to $-79^{\circ} \mathrm{C}$ with dimethyl sulphoxide or glycerol or both compounds. Aust. 7 . biol. Sci. 18, 887.

NAsH, T. (1962) The chemical constitution of compounds which protect erythrocytes against freezing damage. F. gen. Physiol. 46, 167.

SAdleir, R. M. F. S. (1966) The preservation of mammalian spermatozoa by freezing. Lab. Pract. 15, 413.

SawadA, Y. (1964) The preservation of human semen by deep freezing. Int. F. Fert. 9, 525.

Sherman, J. K. (1963) Improved methods of preservation of human spermatozoa by freezing and freeze-drying. Fert. Steril. 14, 49.

Zimmerman, S. J., Maude, M. B. \& Moldawer, M. (1964) Freezing and storage of human semen in 50 healthy medical students. A comparative study of glycerol and dimethyl sulphoxide as a preservative. Fert. Steril. 15, 505. 